\title{
RECURRENT POSTERIOR DISLOCATION OF THE ELBOW JOINT IN A BOY
}

\author{
Report of a Case
}

\author{
R. McKellar Hall, Perth, Western Australia
}

A boy ten years of age was seen in the orthopaedic clinic in May 1948 when he stated that he had first sustained a posterior dislocation of the left elbow joint two vears before; at that time radiographs revealed no evidence of fracture (Fig. 1) and the dislocation had

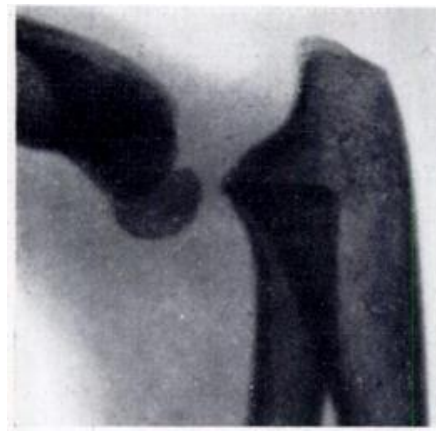

FIG. 1

Radiograph of the elbow at the time of the initial injury, showing posterior dislocation but no evidence of fracture.

been reduced under a general anaesthetic. Redislocation occurred twice in the next year and on each occasion a general anaesthetic had been needed for reduction. Despite physical treatment designed to encourage muscular development, six further dislocations occurred up to the time of examination. The more recent dislocations had been reduced easily without anaesthesia. Clinical examination showed little difference between the two elbows either clinically or radiologically (Fig. 2).

Treatment-At operation a semilunar piece of bone was taken from the upper part of the crest of the tibia and inserted into the coronoid process of the ulna (Fig. 3). The arm was then retained in a cuff and collar sling until the graft was judged to be incorporated. Progress-Apart from a crack-fracture of the donor bone two months after operation the subsequent history has been uneventful. The patient was last seen one vear after operation. There has been no further dislocations and the graft, though somewhat smaller than originally (Fig. 4), appeared to be effective.

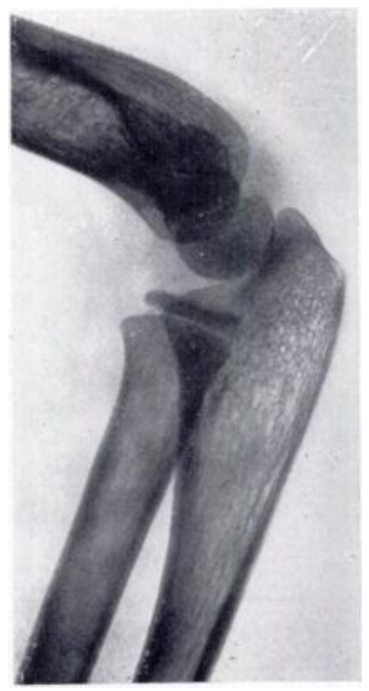

FIG. 2

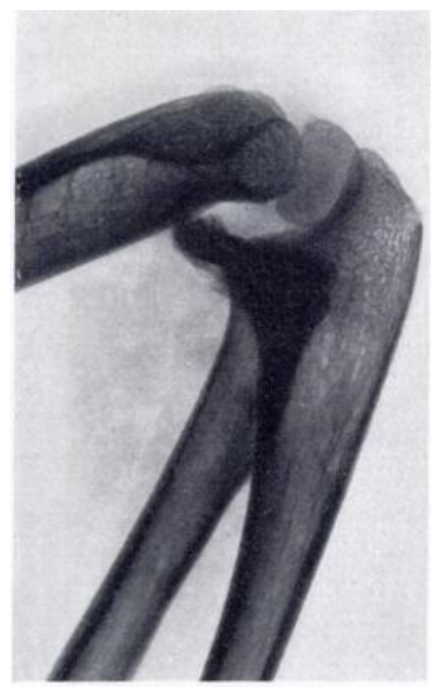

FIG. 3

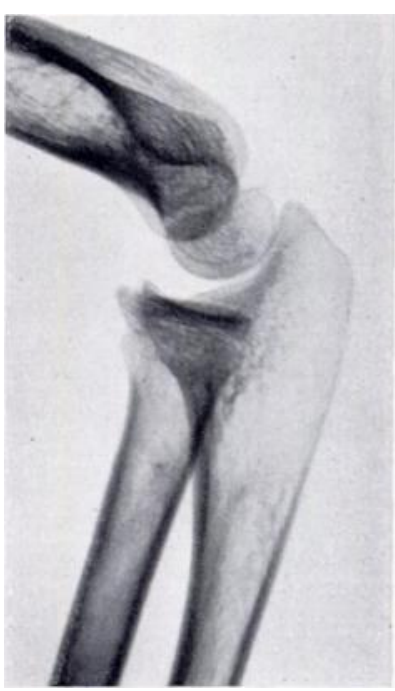

FIG. 4

Figure 2-Before operation. Figure 3-Two months after operation showing bone graft united to coronoid process. Figure 4-One year after operation. The graft has been partly absorbed but remains effective. 